\title{
A FORÇA MAIOR COMO EXCLUDENTE DE RESPONSABILIDADE CIVIL E A PANDEMIA DE COVID-19
}

\author{
Roberto Wagner Marquesi* \\ Marília Barros Breda**
}

\section{Resumo}

Após o advento da responsabilidade civil objetiva, somente a interrupção do nexo causal poderá afastar a condenação do réu. Assim, o problema a ser enfrentado está em analisar se a pandemia de Covid-19 pode ser considerada como força maior, rompendo o nexo causal. Valendo-se do método hipotético-dedutivo, busca-se compreender a evolução da responsabilidade civil, com ênfase na força maior como excludente de responsabilidade. Conclui-se que caracterização da pandemia de Covid-19 como força maior dependerá da análise do caso concreto, não sendo possível a adoção de solução linear.

Palavras-chave: Covid-19; excludente de responsabilidade; força maior; pandemia; responsabilidade civil.

\section{MAJEURE FORCE AS EXCLUDING CIVIL LIABILITY AND THE COVID-19 PANDEMIC}

\begin{abstract}
After the advent of the objective theory, only the casual nexus interruption can make the offender to be considered innocent. The problem to be faced is to analyze whether the Covid19 pandemic can be considered as majeure force, interrupting the bonds between the plaintiff and the defendant. By using the hypothetical-deductive method, the text seeks to understand the evolution of tort law, emphasizing the majeure force as a hypothesis of excluding liability. The characterization of the Covid-19 pandemic as a majeure force will depend on the analysis of the concrete case, not being possible to adopt a linear solution.
\end{abstract}

Keywords: Civil liability; Covid-19; liability exclusion; majeure force; pandemic.

\section{INTRODUÇÃO}

Tradicionalmente, o sistema da responsabilidade civil estava fundamentado em três

\footnotetext{
* Doutor e mestre em Direito Civil pela USP. Mestre em Direito Negocial pela Universidade Estadual de Londrina (1997). Professor adjunto da Universidade Estadual de Londrina, da Pontifícia Universidade Católica do Paraná, campus Londrina, da Escola Superior da Advocacia do Paraná e da Escola do Ministério Público do Paraná. Coordenador do Curso de Especialização em Direito Civil pela Universidade Estadual de Londrina. Advogado.E-mail: wagnermarquesi@uol.com.br.

** Mestranda em Direito Negocial pela Universidade Estadual de Londrina. Pós-graduada em Direito Civil e Direito do Consumidor pela PUCPR - Campus Londrina (2014). Especialista em Direito Empresarial pela PUCPR - Campus Londrina (2012). Advogada.E-mail: marilia.barros@uel.br.
} 
pilares: culpa, dano e nexo de causalidade. Assim, para que surgisse o dever de indenizar era imprescindível que a vítima comprovasse a culpa do agente, compreendida na negligência, imperícia ou imprudência.

Contudo, a dificuldade em se comprovar a ocorrência da culpa foi se intensificando cada vez mais, especialmente com o desenvolvimento do capitalismo industrial e de novas tecnologias, resultando em injustiças por dificultar o acesso concreto da vítima à reparação dos danos por ela sofridos.

Diante desse cenário, a doutrina passou a investigar critérios objetivos de imputação de responsabilidade que pudessem substituir ou ao menos atenuar o papel central da culpa.

Com o advento da responsabilidade civil objetiva, as atenções se voltaram para o nexo de causalidade, pois somente a sua interrupção seria capaz de afastar a condenação do réu. E dentre as situações que podem levar a este rompimento, o presente trabalho se voltará para a figura do caso fortuito ou força maior.

Esta escolha se justifica à medida em que desde março de 2020 o mundo enfrenta uma pandemia causada pelo novo coronavírus (Covid-19), cujos impactos são inúmeros, repercutindo, inclusive, nas relações contratuais, com a impossibilidade de cumprimento das obrigações pendentes, gerando responsabilidades.

Desta forma, o problema a ser enfrentado repousa na necessidade de se investigar as hipóteses em que a pandemia de Covid-19 pode ser considerada como caso fortuito ou força maior e, assim, romper o nexo causal, afastando a responsabilidade civil.

Nesse sentido, valendo-se do método hipotético-dedutivo, buscar-se-á compreender a evolução do instituto da responsabilidade civil, com ênfase na força maior como excludente do dever de indenizar.

Para tanto, o primeiro tópico será dedicado à análise dos elementos da responsabilidade civil, partindo-se da culpa até o desenvolvimento da responsabilidade civil objetiva.

Em seguida, será estudado o conceito de dano, tanto patrimonial quanto extrapatrimonial para, então, abordar as questões relacionadas ao nexo de causalidade, terceiro elemento da responsabilidade civil e considerado o mais difícil de ser determinado.

No último tópico, realizar-se-á a análise da força maior como excludente de causalidade, inclusive quanto à sua gradual relativização e incidência no contexto da pandemia de Covid-19. 


\section{OS ELEMENTOS DA RESPONSABILIDADE CIVIL}

O conceito de responsabilidade civil está atrelado à ideia de ressarcimento, de modo a reestabelecer o equilíbrio entre a vítima e o causador do dano, sendo este um dos elementos necessários para configurar o dever de indenizar.

O sistema de responsabilidade civil consagrado pelas grandes codificações estava fundado em três pilares, consistentes na culpa, nexo de causalidade e dano, cabendo à vítima de um dano demonstrar o caráter culposo da conduta do ofensor e o nexo de causalidade entre essa conduta e o dano.

Por dificultar eventual responsabilização, essas barreiras já foram chamadas de "filtros da responsabilidade civil", como bem destaca Anderson Schreiber (SCHREIBER, 2005, p. 47), já que cabia a vítima de um dano comprovar, além da sua ocorrência, a culpa do ofensor e o nexo de causalidade entre ela e o dano.

Entretanto, com o desenvolvimento do capitalismo industrial e de novas tecnologias, a dificuldade em se comprovar a ocorrência da culpa foi se intensificando e resultando em injustiças por dificultar o acesso concreto da vítima à reparação dos danos por ela sofridos.

Além do mais, o advento da responsabilidade civil objetiva transformou consideravelmente a atuação dos tribunais de maneira geral, exigindo atenção redobrada quando da análise do nexo causal.

Esse cenário de transformações trouxe inovações consideráveis ao instituto, proporcionando discussões a respeito de novos problemas que demandam novas soluções especialmente após a pandemia de Covid-19, que demanda a necessidade de se revisitar institutos, como a força maior como excludente de responsabilidade.

Antes, porém, mister se faz compreender a culpa como fundamento da responsabilidade civil, o advento da responsabilidade civil objetiva, o conceito dano ressarcível e em que consiste o nexo de causalidade.

\subsection{A noção de culpa e a responsabilidade objetiva}


O sistema da responsabilidade civil previsto no Código Civil brasileiro de 1916 estava fundado na prática de um ato ilícito, cujo elemento nuclear era a culpa. Segundo Anderson Schreiber (2011, p. 11):

\begin{abstract}
A culpa é, inegavelmente, a categoria nuclear da responsabilidade civil concebida pelos juristas da Modernidade. A ideologia liberal e individualista, então dominante, impunha a construção de um sistema de responsabilidade que se fundasse no mau uso da liberdade individual, justificando, desta forma, a concessão de um amplo espaço à atuação dos particulares. Responsabilidade e liberdade passam, assim, a ser noções intimamente vinculadas, uma servindo de fundamento à outra.
\end{abstract}

Inicialmente, a culpa era conceituada como "um erro de conduta, cometido pelo agente que, procedendo contra direito, causa dano a outrem, sem a intenção de prejudicar, e sem a consciência de que seu comportamento poderia causá-lo" (PEREIRA, 2012, p. 97).

Contudo, a noção de culpa alterou-se profundamente, saindo de cena a noção de culpa psicológica, base da responsabilidade civil do século XIX, dando lugar à culpa normativa, "que traduz, em breve síntese, o desrespeito a padrões objetivos de comportamento exigíveis no caso concreto" (PEREIRA, 2014, p. 97).

A culpa, também definida como a negligência, imperícia ou imprudência, possui como elementos uma conduta voluntária, com resultado involuntário, previsão ou previsibilidade e falta de cuidado, cautela, diligência ou atenção.

Como se vê, há uma atribuição em maior ou menor grau de um caráter moral à culpa, com ênfase em se verificar a existência de um comportamento reprovável por parte do causador do dano. Como consequência, "a associação da conotação psicológica da culpa com uma rigorosa exigência de sua demonstração conduziu, gradativamente, à modelagem jurisprudencial e doutrinária de um obstáculo verdadeiramente sólido para a reparação dos danos" (SCHREIBER, 2011, p. 16).

Entretanto, após as profundas mudanças sociais provocadas pela Revolução Industrial, os acidentes causados pela utilização de técnicas ainda em desenvolvimento multiplicaram-se, fazendo com que as insuficiências da responsabilidade civil individual e subjetiva viessem à tona (VINEY, 2008, p. 26).

Este fenômeno, cumpre observar, não se trata de exclusividade do direito brasileiro, sendo igualmente relatado por Geneviève Viney o progresso da responsabilidade civil objetiva, ou de "pleno direito", tendências consideradas pela autora como "irmãs gêmeas": 
Déclin de la responsabilité individuelle, progrès des resposabilités « objectives » ou « de plein droit »: telles sont en effet les deux tendence jumelles dont les progrès ont frappé tous les observateurs ( $§ 1$ ). [...] Mais en élargissant son champ d'investigation à l'ensemble des institutions qui concourent à la réparation des dommages, il s'apercevrait également que la résponsabilité est aujourd'hui très largement concurrencée par d'autres procédés permettant la prise en charge direct de certains risques par la collectivité, ce qui l'aménerait peut-être à s'interroger sur la place qui revient aujourd'hui à cette institution dans cet ensemble complexe $(\S 2)$ (VINEY, 2008, p. 29). ${ }^{1}$

A partir de então, a responsabilidade civil começou a ocupar lugar central dentre as preocupações dos civilistas, notadamente em relação à necessidade de se flexibilizar ou mesmo afastar a culpa, com o fim de resolver os problemas decorrentes da reparação dos danos, ante as inúmeras injustiças impostas pela dificuldade de sua demonstração.

Segundo Anderson Schreiber, como "fruto profícuo desse debate, a responsabilidade objetiva veio a ser adotada em quase todos os ordenamentos jurídicos, por meio de leis especiais, aplicáveis a setores específicos, relacionados aos anseios sociais mais graves no campo da responsabilidade civil” (SCHREIBER, 2011, p.19).

No Brasil, a responsabilidade objetiva ingressou efetivamente no ordenamento positivo por meio de leis especiais, tendo a Constituição Federal de 1988 aberto novos caminhos, ao prever novas hipóteses específicas de responsabilidade objetiva (art. $7^{\circ}$, XXVIII; art. 21, XXIII, c; art. 37, § $6^{\circ}$ ), inaugurando "uma nova tábua axiológica, mais sensível à adoção do risco como fundamento de responsabilidade" (SCHREIBER, 2005, p. 49-50).

Seguindo esta tendência, o Código Civil de 2002 converteu em objetiva a responsabilidade aplicável a uma série de hipóteses antes dominadas pela culpa presumida, como a responsabilidade por fato de terceiro e por fato de animais.

Inclusive, o Código Civil de 2002 seguiu a orientação constitucional e instituiu, no parágrafo único do art. 927, verdadeira cláusula geral de responsabilidade civil para atividades de risco.

\footnotetext{
${ }^{1}$ Em livre tradução: "Declínio da responsabilidade individual, progresso das responsabilidades 'objetivas' ou 'de pleno direito': essas são de fato duas tendências gêmeas cujo progresso atingiu todos os observadores (§ 1) [...]. Mas, ao alargar o seu campo de investigação a todas as instituições que contribuem para a reparação de danos, perceber-se-ia igualmente que a responsabilidade é hoje muito concorrida com outros procedimentos que permitem a assunção direta de certos riscos pela coletividade, o que poderia levar ao questionamento sobre o lugar que hoje pertence a esta instituição neste conjunto complexo (§ 2)."
} 
Esta ampla difusão da responsabilidade objetiva comprova a "decadência das concepções elaboradas no âmbito do individualismo jurídico para regular os problemas mais agudos da sociedade atual" (MORAES, 2010, p. 402).

Assim, dentre as principais tendências da responsabilidade civil pode-se citar a chamada erosão dos filtros tradicionais da responsabilidade civil, consistente na perda da importância da prova da culpa e do nexo de causalidade, que será analisado mais adiante.

Em todo caso, o que se verifica é a transferência ou eliminação do ônus da prova da culpa e a relativização da importância da prova do nexo causal, decorrente de sua flexibilização, com a finalidade de assegurar à vítima de um dano alguma reparação.

José Jairo Gomes fundamenta essa mudança de paradigma na solidariedade e cooperação, que funcionariam como princípios hermenêuticos, influindo diretamente na aplicação do Direito (2010, p. 262). Para o referido autor, "sob a ótica solidarista, importa, antes, não deixar a vítima ao desamparo, mas a verdade é que nem sempre ela poderá ser amparada! [...] Eis aí um dos aspectos da necessária relação entre solidariedade e a cooperação, de um lado, e a responsabilidade de outro" (GOMES, 2010, p. 262).

Em verdade, a chamada "erosão" dos filtros da responsabilidade civil demonstra a tendência da jurisprudência em deslocar o foco em direção ao dano, no sentido de assegurar, por qualquer meio disponível, a reparação integral dos prejuízos suportados pela vítima.

\subsection{Conceito de dano}

O dano é um dos elementos necessários à configuração da responsabilidade civil. Contudo, ainda que sejam inúmeras as situações do quotidiano que possam causar danos, somente interessa à responsabilidade civil aqueles que constituem requisito da obrigação de indenizar.

Assim, para que se tenha uma compreensão exata da responsabilidade civil é preciso que se estabeleça a noção de dano e, em especial, de dano ressarcível e suas subdivisões.

Como visto, o conceito de responsabilidade civil está atrelado à ideia de ressarcimento, de modo a reestabelecer o equilíbrio entre a vítima e o causador do dano, sendo este um dos elementos necessários para configurar o dever de indenizar.

Parte da doutrina tem optado, inclusive, por substituir a expressão "responsabilidade civil" por "direito de danos", em razão do "fenômeno da pavimentação da objetivação da 
imputação de danos, paulatinamente construída pela eliminação dos tradicionais muros de contenção à obrigação de indenizar", fazendo com que "a atividade preponderante do julgador nas pretensões compensatórias consista em avaliar se há um dano injustificado" (ROSENVALD, 2021, p. 307).

Do mesmo modo, destaca-se o deslocamento do eixo da responsabilidade civil para o fato jurídico lesivo, num fenômeno chamado por Nelson Rosenvald de “"big bang' de interesses merecedores de tutela" (ROSENVALD, 2021, p. 308).

Diante disso, a fim de apresentar um conceito de dano, destaca-se as lições de José Dias de Aguiar, para quem o dano pode ser conceituado como resultado da lesão a um direito (DIAS, 2012, p. 821).

A partir desse conceito, verifica-se a necessidade de diferenciar lesão, dano e prejuízo: enquanto a lesão está relacionada ao ato causador do dano, este "se apresenta como consequência daquela e deve ser reparado pelo lesante, em razão de sua responsabilidade, apurando-se os prejuízos suportados no patrimônio da vítima, seja material ou ideal" (AMARAL; PONA, 2014, p. 248).

Desta forma, tem-se que o dano ressarcível pode ser subdivido em danos patrimoniais e extrapatrimoniais, que comportam, igualmente, subcategorias, conforme se verá adiante.

Antes, porém, importa ressaltar que o dano, para ser considerado ressarcível, deve resultar em um prejuízo certo, ainda que seus efeitos se produzam em relação ao futuro, impedindo ou diminuindo o benefício patrimonial da vítima (dano emergente e lucros cessantes), não se justificando, porém, a reparação do dano hipotético.

Este requisito também está presente no direito comparado, como se pode observar das lições de Carlos A. Gherst: "La doctrina tradicional imponía e impone al daño los siguientes requisitos: a) certidumbre; b) que sea personal del accionante, y c) que de él resulte una lesión a un derecho subjetivo o interés legítimo" (GHERST, 1997, p. 47)².

Em relação aos danos patrimoniais, estes podem ser conceituados como os danos "cuja origem seja a lesão que recaia sobre um interesse afeto ao patrimônio da vítima" (AMARAL; PONA, 2014, p. 254), estando neles incluídas as categorias de danos emergentes e lucros cessantes.

\footnotetext{
${ }^{2}$ Em livre tradução: “A doutrina tradicional impôs e impõe aos danos os seguintes requisitos: a) certeza; b) que seja pessoal do autor; e c) que resulta em dano a um direito subjetivo ou interesse legítimo".
} 
Importante destacar a superação da corrente doutrinária que, no passado, procurava identificar o conceito de dano com o dano patrimonial, pois, após a Constituição Federal de 1988, restou expressamente assegurado o direito à indenização por dano material e moral, restando clara a possibilidade de reparação de dano não patrimonial ou extrapatrimonial.

Os danos extrapatrimoniais, portanto, "são os que atingem o lesado em seus valores não econômicos, em seu patrimônio psicológico, tranquilidade psíquica, os chamados direitos da personalidade, como honra, nome, imagem" (AMARAL; PONA, 2014, p. 245).

Através desse conceito é possível perceber que dano extrapatrimonial e dano moral não se equivalem. Em verdade, o dano extrapatrimonial pode ser considerado um gênero do qual se subdividem quatro espécies de danos: dano à imagem, dano estético, dano existencial e, enfim, o dano moral.

De maneira bastante suscinta, pode-se dizer que o dano à imagem ocorre quando há sua indevida captação, independentemente de qualquer lesão à honra ou à vida privada da vítima.

O dano estético, por sua vez, tem adquirido o relevo funcional, indo além do "enfeamento" da vítima, sendo percebido como um significativo desequilíbrio corporal infligido à pessoa.

Já o dano existencial, pode ser conceituado como uma "modificação prejudicial relevante na vida de uma pessoa decorrente de um fato danoso" (ROSENVALD, 2021, p. 311).

Diante disso, Nelson Rosenvald defende que o dano moral deve operar por exclusão,

impondo-se sempre que a lesão a um interesse existencial concretamente merecedor de tutela não ocorra nos territórios da indevida captação da imagem ou da funcionalidade orgânica. Assim, ofensas à reputação, privacidade, integridade psíquica, liberdade e solidariedade ainda se inserem nas lindes do dano moral (ROSENVALD, 2021, p. 312).

Ainda segundo Nelson Rosenvald, essa taxonomia se faz necessária a fim de "viabilizar, na medida do possível, uma reparação integral, evitando-se a transformação da amplitude da expressão 'dano moral' em uma 'guerra de etiquetas', a ponto de o dano extrapatrimonial ser qualquer coisa e qualquer coisa ser nada..." (ROSELVALD, 2021, p. 313). 
Desta forma, pode-se concluir que os conceitos de dano moral e dano extrapatrimonial, não mais se confundem, sendo o primeiro, espécie do gênero "dano extrapatrimonial", do qual também fazem parte os danos à imagem, estético, existencial.

Atualmente, o que se tem visto é uma expansão desmedida dos danos ressarcíveis, que desafiam a doutrina e a jurisprudência e demanda uma transformação na forma de abordálos, a fim de que sejam elaborados critérios para a seleção dos interesses merecedores de tutela, em conformidade com os valores fundamentais do ordenamento jurídico brasileiro evitando-se, dessa forma, a proliferação de demandas ressarcitórias de caráter fantasioso.

\subsection{Nexo de causalidade}

O nexo de causalidade, por sua vez, é considerado o mais delicado dos elementos da responsabilidade civil e o mais difícil de ser determinado (PEREIRA, 2012, p. 106). Trata-se da primeira questão a ser enfrentada quando do julgamento das demandas indenizatórias, pois, para que haja o dever de indenizar, é imprescindível a demonstração do nexo causal entre o ato culposo ou a atividade objetivamente considerada e o resultado danoso.

Ademais, a importância do estudo do conceito de nexo de causalidade decorre da “proliferação de novas hipóteses de responsabilidade e do desprestígio do papel da culpa, inapta a servir de critério seguro ao julgador na determinação do dever de indenizar" (PEREIRA, 2012, p. 107).

Assim, para se compreender em que consiste o nexo de causalidade, é fundamental que se tenha em mente, como bem observado por Savatier, que "coincidência não implica em causalidade" (SAVATIER apud PEREIRA, 2012, p. 106).

Usualmente, a relação de causalidade é definida como o liame existente entre dois eventos, sendo um, consequência do outro. A simplicidade dessa definição, porém, esconde as reais dificuldades práticas dela decorrentes, ante a necessidade de se limitar o conceito de causa de modo a evitar uma responsabilização demasiadamente ampla.

Além do mais, tanto a doutrina nacional quanto a estrangeira não são uníssonas em relação às teorias existentes, sendo algumas tratadas como sinônimos por uns, e de forma diferenciada, por outros. 
A fim de se evitar, portanto, maiores confusões terminológicas, adota-se neste trabalho a classificação proposta por Anderson Schreiber, na obra "Novos Paradigmas da Responsabilidade Civil: da erosão dos filtros da reparação à diluição dos danos” (2011).

Diante desse cenário, dentre as diversas teorias existentes acerca da causalidade jurídica, podem ser destacadas as seguintes: (i) a teoria da equivalência das condições, (ii) a teoria da causalidade adequada, (iii) a teoria da causalidade eficiente e (iv) a teoria da causa direta e imediata.

A primeira delas, chamada de teoria da equivalência das condições ou teoria da conditio sine qua non, é a mais antiga e considera que todas as condições de um dano se equivalem, consistindo em causas do prejuízo todos os antecedentes que concorreram de alguma maneira para a sua realização.

Esta teoria é criticada por atribuir a um dano um número infinito de causas. Philippe Malaurie e Laurent Aynés, aliás, afirmam que essa infinidade de causas "tenderiam a tornar cada homem responsável por todos os males que atingem a humanidade" (MALAURIE; AYNÉS apud PEREIRA, 2012, p. 110).

As dificuldades decorrentes da teoria da equivalência das condições levou a doutrina a desenvolver uma segunda teoria, chamada de "causalidade adequada", concebida por Von Bar e aprimorada, anos depois, pelo filósofo Von Kries, no final do séc. XIX.

De acordo com essa teoria, a causa de um evento seria aquela mais apta, em abstrato, à produção de determinado resultado. Segundo Anderson Schreiber, o que se busca é identificar, na presença de mais de uma possível causa, qual delas, independentemente das demais, é potencialmente apta a produzir os efeitos danosos: "Esta condição seria a causa adequada do dano (e daí o nome da teoria); as demais condições seriam circunstâncias não causais" (SCHREIBER, 2011, p. 58).

Contudo, com o passar do tempo, esta teoria também entrou em desprestígio, sendo inclusive associada à teoria da equivalencia das condições, em razão da indefinição do que seria "adequado", conceito que estaria atrelado ao grau de probalidade do dano. E, nas palavras de Caio Mário da Silva Pereira, “probabilidade não é certeza” (PEREIRA, 2012, p. 111).

Formulou-se, então, a teoria da causalidade eficiente. Para essa teoria, "as condições que concorrem para um certo resultado não são equivalentes, existindo sempre um 
antecedente que, em virtude de um intrínseco poder qualitativo ou quantitativo, elege-se como verdadeira causa do evento" (SCHREIBER, 2011, p. 59-60).

Isto é, a causalidade seria determinada de acordo com cada caso concreto, devendo ser observado pelo julgador, dentre as diversas causas possíveis, qual teria sido a mais eficiente para a produção do evento danoso.

Assim, em sentido oposto à teoria da causalidade adequada, a teorida causalidade eficiente peca pela falta de rigor científico, em razão do empirísmo que permeia a sua aplicação.

Ao depois, ganhou destaque a teoria da causalidade direta e imediata, também chamada de teoria da interrupção do nexo causal, que considera como causa apenas o evento diretamente vinculado ao dano, restringindo-se aos acontecimentos mais próximos do dano.

Esta teoria acabou positivada em uma série de ordenamentos jurídicos, inclusive pelo Código Civil brasileiro de 1916 (art. 1.060), mantida pelo Código Civil de 2002, em seu art. 403, com a seguinte redação: "Ainda que a inexecução resulte de dolo do devedor, as perdas e danos só incluem os prejuízos efetivos e os lucros cessantes por efeito dela direto e imediato, sem prejuízo do disposto na lei processual" [destacou-se].

Contudo, aos poucos percebeu-se que a teoria da causalidade direta e imediata poderia ser excessivamente restritiva, impossibilitando, assim, a reparação da vítima, pois excluiria da ressarcibilidade os danos indiretos ou remotos.

A fim de combater as injustiças decorrentes dessa limitação, desenvolveu-se no âmbito da própria teoria da causalidade direta e imediata, a chamada subteoria da necessariedade causal.

Para essa teoria, as expressões dano direto e dano imediato são entendidas de forma substancial, "como reveladoras de um liame de necessariedade - e não de simples proximidade - entre a causa e o efeito. Haverá, assim, dever de reparar, quando o evento danoso for efeito necessário de determinada causa" (SCHREIBER, 2011, p. 61-62).

Como se não bastassem as incertezas das teorias relacionadas ao nexo de causalidade, sob o ponto de vista teórico, a análise jurisprudencial revela o surgimento de inúmeras teorias, utilizadas muitas vezes para justificar uma escolha subjetiva do julgador e, assim, fundamentar a reparação de um dano. Esta conduta é objeto de severas críticas por parte de Anderson Schreiber: 
O que se vê, em muitos casos, é que os tribunais, muito pelo contrário, se valem da miríade de teorias exatamente para justificar uma escolha subjetiva, e muitas vezes atécnica, da causa do dano. Com efeito, expressões como 'causalidade adequada' e 'causalidade eficiente' têm sido empregadas, frequentemente, em procedimentos racionais que refletem o uso de outras teorias, como a subteoria da necessariedade. Em outros casos, tais expressões têm sido usadas mesmo sem refletir qualquer construção teórica, mas tão-somente a eleição, com ampla discricionariedade, da causa que, no entendimento do magistrado, melhor assegura proteção à vítima (SCHREIBER, 2005, p. 53).

E mais adiante, prossegue o autor afirmando que, "não apenas se verifica um emprego muitas vezes atécnico das construções teóricas acima examinadas, como se nota uma verdadeira profusão de raciocínios inconciliáveis que desafiam a redução das decisões judiciais a um posicionamento minimamente uniforme" (SCHREIBER, 2011, p. 62-63).

Importante ressaltar que essas dificuldades em se determinar o conceito de nexo de causalidade também estão presentes no Direito italiano e francês. Suzanne Carval, por exemplo, reconhece que o problema da causalidade não pode ser resolvido com uma única redação rígida:

Che non si tratti qui dell'applicazione di un concetto di "causalità" precostituito all'indagine giuridica fu chiaro a quegli scritatori che portarono i maggiori contributi alla soluzione del problema; ma il carattere relativo e pragmatico dei concetti che essi proposero, e che si affermarono nella dottrina giuridica, troppo spesso fu perso di vista in séguito: da ciò la reazione della doctrina più recente, che sottolinea la connessione funzionale del criterio limitativo con lo scopo della norma che prescrive la responsabilità, al fine di delimitare quest'ultima in modo conveniente.

Di qui è stato breve il passo a rendersi conto che il problema non è risolubile con una forinula rigida e unitaria, e che in particolari ipotesi operano anche limiti speciali, connessi con lo scopo della singola norma dla cui deriva la responsabilità (CARVAL, 1993, p. 02). ${ }^{3}$

No direito francês, também é possível verificar a dificuldade de se determinar em quais casos é possível dizer que um evento causou um dano, não havendo, assim como no Brasil, uma correspondência exata entre as teorias desenvolvidas pela doutrina e a utilizada pelos tribunais. A esse respeito, tem-se as lições de Muriel Fabre-Magnan, professora na Escola de Direito da Sorbonne - Universidade de Paris I (Panthéon-Sorbonne):

\footnotetext{
${ }^{3}$ Em livre tradução: "Não se trata aqui da aplicação de um conceito de "causalidade" preconcebido à investigação jurídica tendo ficado claro para aqueles escritores que trouxeram as maiores contribuições para a solução do problema; mas o caráter relativo e pragmático dos conceitos que propunham, e que se afirmavam na doutrina jurídica, muitas vezes se perdeu de vista posteriormente: daí a reação da doutrina mais recente, que sublinha a ligação funcional do critério limitador com a finalidade da norma que prescreve a responsabilidade, a fim de delimitar esta última de modo conveniente.

Daí foi um passo curto perceber que o problema não pode ser resolvido com uma redação rígida e unitária, e que em hipóteses particulares também operam limites especiais, vinculados ao propósito da norma única da qual deriva a responsabilidade"
} 
la notion de causalité est riche de potentialités théoriques et la doctrine a de quoi gloser sur une question aussi mythique que celle des causes [...] Différentes théories ont alors été proposées par la doctrine, mais elles sont rarement reprises par la Cour de cassation, et surtout aucune d'elle n'a jamais été choisie comme étant la définition 'officielle' du lien de causalité (FABRE-MAGNAN, 2007, p. 199). ${ }^{4}$

Não se pode olvidar, ainda, o advento da responsabilidade objetiva, que transformou radicalmente a atuação dos tribunais, pois, ao desvincular o dever de reparar da culpa do sujeito, somente a interrupção do nexo causal é que poderá possibilitar ao réu afastar a sua condenação.

Anderson Schreiber afirma, inclusive, que o juízo de responsabilidade, nos casos de reponsabilidade objetiva, 'acaba por traduzir-se no juízo sobre a existência de nexo de causalidade entre fato e dano"" (SCHREIBER, 2011, p. 56).

Desta forma, o nexo causal pode ser rompido e, assim, excluído o dever de indenizar, em três situações: i) culpa exclusiva da vítima; ii) fato de terceiro; e iii) caso fortuito ou força maior. Estes fatores rompem o liame de causalidade entre a atividade do agente e o dano por serem estranhos à cadeia causal.

A seguir, realizar-se-á uma análise mais detida da força maior como excludente de causalidade, inclusive quanto à sua gradual relativização e incidência do contexto da pandemia de Covid-19.

\section{A FORÇA MAIOR COMO EXCLUDENTE DE RESPONSABILIDADE CIVIL}

Como visto, dentre os fatores que podem resultar no rompimento do nexo causal e, consequentemente, afastar o dever de indenizar, tem-se o caso fortuito e a força maior. Por vezes considerados como sinônimos por parte da doutrina, ambos são eventos externos, completamente alheios à vontade do agente e de seu controle, podendo ser diferenciados pela imprevisibilidade e irresistibilidade do evento. Isto é,

estaremos em face do caso fortuito quando se tratar de evento imprevisível e, por isso, inevitável; se o evento for inevitável, ainda que previsível, por se tratar de fato

\footnotetext{
${ }^{4}$ Em livre tradução: "a noção de causalidade é rica em potencialidades teóricas e a doutrina tem algo a que se debruçar sobre uma questão tão mítica quanto a das causas [...]. Diferentes teorias foram então propostas pela doutrina, mas raramente elas são retomadas pelo Tribunal de Cassação e, especialmente, nenhuma delas jamais foi escolhida como a definição 'oficial' do vínculo causal".
} 
superior às forças do agente, como normalmente são os fatos da Natureza, como as tempestades, enchentes etc., estaremos em face da força maior, como o próprio nome diz. É o act of God, no dizer dos ingleses, em relação ao qual o agente nada pode fazer para evitá-lo, ainda que previsível (CAVALIERI FILHO, 2014, p. 89).

José Aguiar Dias, por sua vez, trata ambos os termos como sinônimos, como pode ser observado no excerto a seguir reproduzido:

\begin{abstract}
Segundo a autorizada lição de Arnoldo Medeiros, a noção de caso fortuito ou de força maior decorre de dois elementos: um interno, de caráter objetivo, ou seja, a inevitabilidade do evento; outro, externo ou subjetivo, a ausência de culpa. Adota, pois um conceito misto e não há senão aceitar-lhe a lição no sentido de que '[...] não há acontecimentos que possam, a priori, ser sempre considerados casos fortuitos; tudo depende das condições de fato em que se verifique o evento. O que é hoje caso fortuito, amanhã deixará de sê-lo, em virtude do progresso da ciência ou da maior providência humana (DIAS, 2012, p. 791-791).
\end{abstract}

No mesmo sentido, Geneviève Viney considera o caso fortuito e a força maior como sinônimos, vez que o Código Civil francês faz referência às duas expressões e, às vezes, de forma simultânea:

L'expression "force majeur », qui exprime l'idée de contrainte irrésistible, est tradionelle dans la langue juridique française. Elle est d'ailleurs connue d'autres systèmes juridque et figure dans de nombreuses conventions internationales et notamment dans la convention de Vienne sur la vente internacionale de marchandises (art . 49). Bien qu'elle soit synonyme de «cas fortuit» - expression à laquelle se réfère souvent et parfois simultanément le Code Civil, notamment das l'article 1148 -, elle évoque plus directement la force superièure à celle de l'homme - le vis major - qui l'empêche d'agir comme il aurais voulu ou le contraint à faire ce qu'il ne voulait pas. [...] Ainsi, en matière de responsabilité civile, la force majeur désigne l'événement qui, d'une part, a eu sur la réalisation du dommage une influence si déterminante qu'il a rendu pratiquement négligeable le rôle des autres conditions et qui, d'autre part, a rendu impossible l'exécution des obligations du débiteur ou les respect des devoirs s'imposant normalement à l'agent. C'est pourquoi, conformement à l'adage, «À l'impossible nul n'est tenu », on admet que la force majeur permet au défendeur d'échapper à toute responsabilité (VINEY, 2006, p. 264-265) ${ }^{5}$

\footnotetext{
${ }^{5}$ Em livre tradução: “A expressão 'força maior', que expressa a ideia de constrangimento irresistível, é tradicional na linguagem jurídica francesa. Também é conhecida por outros sistemas jurídicos e aparece em muitas convenções internacionais e, em particular, na convenção de Viena sobre a venda internacional de mercadorias (art. 49). Embora seja sinônimo de 'caso fortuito' - expressão a que o Código Civil se refere frequentemente e por vezes simultaneamente, em especial no artigo 1148 -, ela evoca mais diretamente a força superior àquela do homem - o vis major - que o impede de agir do modo como gostaria ou o obriga a fazer o que não quer. [...] Assim, em matéria de responsabilidade civil, a força maior designa o evento que, por um lado, teve na realização do dano uma influência tão decisiva que tornou praticamente desprezível o papel das demais condições e que por outro lado, impossibilitou o cumprimento das obrigações do devedor ou o cumprimento dos deveres normalmente impostos ao mandatário. É por isso que, de acordo com o ditado, 'Ao impossível ninguém está obrigado', admite-se que a força maior permite ao defensor escapar de qualquer responsabilidade".
} 
Em que pese a ausência de entendimento uniforme quanto ao conceito de caso fortuito e força maior, a sua diferenciação tem pouco efeito prático, pois ambos recebem o mesmo tratamento jurídico conferido pelo art. 393 do Código Civil ${ }^{6}$, qual seja, são considerados como mitigadores da responsabilidade, sendo importante compreender que ambos estão fora dos limites da culpa.

Estabelecida, portanto, a identidade entre o caso fortuito e força maior, é preciso distinguir os seus efeitos quando se trata de responsabilidade civil contratual ou extracontratual. Essa diferenciação se faz necessária à medida em que, em âmbito contratual, a análise dos requisitos da força maior é realizada a partir das circunstâncias existentes no momento da formação do vínculo.

É preciso, ainda, que se leve em consideração as previsões realizadas pelas partes e a eventual distribuição dos riscos, a lembrar que

\begin{abstract}
a própria lei permite que as partes convencionem o deslocamento do risco do fortuito em favor do credor, fazendo com que persista a responsabilidade do devedor, mesmo se a inexecução se der em decorrência de evento inevitável para o qual este não tenha concorrido. Homenageia-se a autonomia privada [...]. Mesmo assim, só se considerarão assumidos pelo devedor os riscos previsíveis na época da celebração do contrato. Se a inexecução se der por causa imprevisível àquele tempo, a transferência dos riscos não se implementará (TEPEDINO; BARBOSA; MORAES, 2004, p. 707).
\end{abstract}

Em relação à responsabilidade extracontratual, a presença de caso fortuito ou de força maior é analisada no momento da ocorrência do dano e, uma vez caracterizado o caso fortuito, o nexo de causalidade é completamente rompido, elidindo a responsabilidade, sendo irrelevante a externalidade do fato "para caracterizar o caso fortuito ou de força maior, pois nestes casos a caracterização da responsabilidade está vinculada à imputação culposa" (KROETZ, 2020).

Contudo, segundo Anderson Schreiber, a jurisprudência atual, em todo o mundo, tem relativizado gradualmente o poder excludente destes fatores, ganhando acolhida "a chamada teoria do fortuito interno, desenvolvida no âmbito das relações de consumo, a fim de evitar a exclusão da responsabilidade do fornecedor por acontecimentos que, embora imprevisíveis e

\footnotetext{
6 “Código Civil Brasileiro. Art. 393. O devedor não responde pelos prejuízos resultantes de caso fortuito ou força maior, se expressamente não se houver por eles responsabilizado. Parágrafo único. O caso fortuito ou de força maior verifica-se no fato necessário, cujos efeitos não era possível evitar ou impedir".
} 
irresistíveis, se verificam anteriormente à colocação do produto no mercado" (SCHREIBER, 2011, p. 68).

Assim, além dos requisitos da imprevisibilidade e irresistibilidade do caso fortuito ou força maior, é preciso demonstrar que este fator é externo àquela relação, sob pena de ser mantida a responsabilidade do agente. Em outros termos, "aos tradicionais requisitos da imprevisibilidade e irresistibilidade do caso fortuito, tem-se acrescentado esta terceira exigência - a externalidade ou externidade do caso fortuito, sem a qual se conserva a responsabilidade" (SCHREIBER, 2011, p. 68-69).

Resta, portanto, investigar se a pandemia de Covid-19 pode ser considerada como caso fortuito a ponto de romper o nexo de causalidade e afastar o dever de indenizar.

\subsection{A força maior e a pandemia de Covid-19}

Em 11 de março de 2020, a Organização Mundial de Saúde classificou como pandemia a disseminação do novo coranavírus. Medidas restritivas foram adotas em todo o mundo, inpactando sobremaneira a economia dos países, inclusive do Brasil, repercutindo inevitavelmente nas relações contratuais, ante a impossibilidade, em alguns casos, de cumprimento das obrigações pendentes nos termos avençados originariamente.

A princípio, a situação pandêmica iniciada em março de 2020 e as medidas excepcionais adotadas pelos governantes para enfrentar a doença poderiam ser consideradas como força maior, porquanto se trata de evento inevitável, irresistível e impossível de controle e, assim, levar à isenção de responsabilidade.

Contudo, a solução não é tão simples tampouco se dá de maneira uniforme. Como bem ressalta Maria Candida do Amaral Kroetz,

As circunstâncias decorrentes da pandemia de Covid-19, bem como as medidas, por sua causa, impostas pelo Estado de restrição de circulação ou de vedação de atividades que gerem aglomeração de pessoas podem configurar, mas nem sempre, $o$ caso fortuito ou de força maior. Para que isso opere, o dano observado deve ser justificado por circunstâncias excepcionais e insuperáveis (KROETZ, 2020).

Quando se trata de responsabilidade civil contratual ou extracontratual objetiva, é preciso que se faça uma análise dos fatos e circunstâncias que permeiam o caso, bem como a atitude e comportamento adotados pelo sujeito para justificar suas ações e omissões. 
A título exemplificativo, Gustavo Tepedino, Milena Donato Oliva e Antonio Pedro Dias citam o caso do pianista contratado para se apresentar na Sala São Paulo, porém as atividades no local foram suspensas pelo Poder Público em decorrência da pandemia (TEPEDINO et. al, 2020). Nesta situação, verifica-se que houve a inexecução involuntária do cumprimento da prestação, caracterizando evento de força maior.

Situação diversa se verifica, por exemplo, quando se trata de transporte áreo contratado no período em que já se encontrava presente o contexto pandêmico. Neste caso, a necessidade de reestruturação da malha área em razão da pandemia de Covid-19 não constitui motivo hábil a elidir o dever de indenizar, tratando-se de fortuito interno. Desta forma, tem-se que

\footnotetext{
a qualificação de determinada situação como caso fortuito ou força maior, portanto, depende da verificação da objetiva possibilidade de adimplemento da prestação, seja por impossibilidade do seu objeto (a prestação não pode ser cumprida por evento externo inevitável), seja do sujeito (acometido por doença que o incapacita de efetuar a prestação)" (TEPEDINO et. al, 2020).
}

Quando se trata de responsabilidade extracontratual subjetiva, porém, é necessário que seja realizada a análise no momento da ocorrência do dano, bastando a ausência de culpa do causador do dano para isentá-lo, pois "ninguém é obrigado a fazer o impossível" (KROETZ, 2020).

Diante disso, a caracterização do caso fortuito ou força maior dependerá da análise do caso concreto, não sendo possível a adoção de uma solução linear e única, até mesmo por conta das características que distinguem a responsabilidade civil quando contratual, extracontratual objetiva e extracontratual subjetiva.

\section{CONSIDERAÇÕES FINAIS}

Nas últimas décadas, foi possível observar uma mudança no cenário da responsabilidade civil, inicialmente ancorada na culpa latu sensu do agente, no dano e no nexo de causalidade.

Com a valorização do papel do interprete e a inclusão de aspectos sociais, econômicos e éticos no debate jurídico, a responsabilidade civil sofreu transformações, com a relativa perda de importância da prova da culpa e do nexo de causalidade. 
Este fenômeno decorre não apenas do advento da responsabilidade objetiva, mas também das transformações ocorridas no âmbito da própria responsabilidade por ato ilícito. Como consequência da facilitação da prova da culpa, tem-se o considerável aumento do fluxo de ações de indenização.

De modo semelhante, verifica-se que a prova do nexo causal também tem sido flexibilizada pelos tribunais, ante a necessidade de se assegurar alguma reparação às vítimas de um dano. Até mesmo as excludentes do nexo de causalidade, como o caso fortuito ou força maior têm sido relativizadas, a fim de manter a responsabilidade do agente quando se está diante de um fortuito interno.

Além do mais, a pandemia de Covid-19, com as consequentes medidas restritivas impostas pelo Poder Público na tentativa de controlar a propagação da doença, impôs a necessidade de se refletir quanto à possibilidade de ela ser considerada ou não como excludente do dever de indenizar.

Como visto, a caracterização do caso fortuito ou força maior dependerá da análise do caso concreto, não sendo possível a adoção de uma solução linear e única, até mesmo por conta das características que distinguem a responsabilidade civil contratual, extracontratual objetiva e extracontratual subjetiva.

Ademais, ainda que os tribunais tenham voltado o foco em direção ao dano, não se pode olvidar que nem sempre haverá a exata recomposição patrimonial, porquanto a vida social impõe a todos a assunção de certos prejuízos e a exposição a certos riscos, além de ser necessária elaboração de critérios de seleção dos interesses merecedores de tutela, em conformidade com os valores fundamentais do ordenamento jurídico brasileiro.

Diante disso, pode-se concluir que, mesmo não sendo possível a adoção de uma solução única quanto aos impactos da pandemia do novo coronavírus nas responsabilidade civil, a doutrina possui critérios jurídicos suficientes para análise dos casos concretos, garantindo a tão almejada segurança jurídica esperada.

\section{REFERÊNCIAS}

AMARAL, Ana Cláudia Corrêa Zuin Mattos do Amaral; PONA, Everton Willian. Delimitando conceitos: do jurídico ao econômico e a adequada compreensão do patrimônio como meio indireto de tutela da pessoa humana. In: Girolamo Domenico Treccani; Joyceane Bezerra de Menezes; Lucas Abreu Barroso. (Org.). Direito Civil II. João Pessoa: Conpedi, 2014, p. 236-262. 
BRASIL. Constituição da República Federativa do Brasil de 1988. Disponível em: <http://www.planalto.gov.br/ccivil_03/constituicao/constituicao.htm>. Acesso em: 31 jul. 2021.

Lei $\mathrm{n}^{\circ}$ 10.406, de 10 de janeiro de 2002. Institui o Código Civil. Disponível em: <http://www.planalto.gov.br/ccivil_03/leis/2002/110406compilada.htm>. Acesso em: 31 jul. 2021.

CAVALIERI FILHO, Sérgio. Programa de Responsabilidade Civil. 11. ed. São Paulo: Atlas, 2014.

DIAS, José Aguiar. Da Responsabilidade Civil. 12.ed. Rio de Janeiro: Lumen Juris, 2012.

FABRE-MAGNAN, Muriel. Droits des obligations: 2- Responsabilité civile et quasicontrats. 3.ed. Paris: Presses Universitaires de France, 2007.

GHERST, Carlos A. Teoría General de la reparación de daños: análisis sociológico y económico del daño individual y social, hecho humano, daño y relación de causalidad, autoría, factores de distribución subjetivos y objetivos, acciones de reparación y cuantificación del daño jurisprudencial. Buenos Aires: Astrea, 1997.

GOMES, José Jairo. Responsabilidade Civil na pós-modernidade: influência da solidariedade e da cooperação. In: NERY JUNIOR, Nelson; NERY, Rosa Maria de Andrade. Doutrinas essenciais: Responsabilidade Civil. v. 1. São Paulo: Revista dos Tribunais, 2010.

KROETZ, Maria Cândida do Amaral. Covid-19 e caso fortuito ou de força maior na responsabilidade civil extracontratual (2020). Disponível em:

$<$ https://www.conjur.com.br/2020-jun-29/direito-civil-atual-covid-19-fortuito-

responsabilidade-civil-extracontratual> Acesso em 09.09.2021.

MORAES, Maria Celina Bodin de. Na medida da pessoa humana: estudos de direito civilconstitucional. Rio de Janeiro: Renovar, 2010.

PEREIRA, Caio Maria da Silva; TEPEDINO, Gustavo (atual.). Responsabilidade Civil. 10. ed. Rio de Janeiro: GZ Editora, 2012.

PÜSCHEL, Flavia Portella. Função Punitiva da responsabilidade civil. In: Revista FGV. São Paulo, vo 21, p. 17-36, jul-dez 2007. 
ROSENVALD, Nelson. A responsabilidade civil: compensar, punir e restituir. In: Michel Canuto de Sena (Org). Responsabilidade Civil: aspectos gerais e temas contemporâneos. Campo Grande: Contemplar, 2020, p. 131-140.

Por uma tipologia dos danos extrapatrimoniais. In: PIRES, Fernanda Ivo (org); GUERRA, Alexandre (coord); et.al. Da estrutura à função da responsabilidade civil: uma homenagem do Instituto Brasileiro de Estudos de Responsabilidade Civil (IBERC) ao Professor Renan Lotufo. Indaiatuba: Foco, 2021.

SCHREIBER, Anderson. Novos paradigmas da responsabilidade civil: da erosão dos filtros da reparação à diluição dos danos. 3. ed. São Paulo: Atlas, 2011.

Novas tendências da responsabilidade civil brasileira. In: TEPEDINO, Gustavo.

Revista Trimestral de Direito Civil. n. 22, Rio de Janeiro: Padma, abr.-jun. 2005.

TEPEDINO, Gustavo; BARBOZA, Heloisa Helena; MORAES, Maria Celina Bodin de. Código Civil interpretado conforme a Constituição: Parte Geral e Obrigações (arts. $1^{\circ}$ ao 420). v. 1. Rio de Janeiro: Renovar, 2004.

TEPEDINO, Gustavo; OLIVA, Milena Donato; DIAS, Antônio Pedro. Contratos, força maior, excessiva onerosidade e desequilíbrio patrimonial (2020). Disponível em: $<$ https://www.conjur.com.br/2020-abr-20/opiniao-efeitos-pandemia-covid-19-relacoespatrimoniais> Acesso em: 09.09.2021.

VINEY, Geneviève. Traité de Droit Civil: Les conditions de la responsabilité. 3. ed. Paris: LGDJ, 2006.

Traité de Droit Civil: Introduction à la responsabilité. 3. ed. Paris: LGDJ, 2008. 